\title{
Discusiones sobre el género. Apuntes para una reflexión de la violencia de género en la universidad'
}

\author{
DISCUSSING GENDER. NOTES FOR A REFLECTION ON GENDER VIOLENCE IN COLLEGE
}

\author{
Abel Lozano Hernández \\ Benemérita Universidad Autónoma de Puebla, México, Alozano21@hotmail.com \\ Quetzali Bautista Moreno \\ Benemérita Universidad Autónoma de Puebla, México, quetzalib@yahoo.com.mx
}

Recibido: 6 de marzo, 2015 Aceptado: 24 de noviembre, 2015

\begin{abstract}
Resumen:Enel presentetrabajo se presentan algunas manifestaciones deviolencia degénero en un campus de la Benemérita Universidad Autónoma de Puebla, BUAP. La información obtenida en campo nos ha llevado a reflexionar sobre los procesos y formas en que los individuos enfrentan cotidianamente los esquemas de género socialmente aprehendidos y expresados en el ejercicio de la vida cotidiana en el ámbito universitario. Se parte de asumir que la violencia de género es estructural y que sus múltiples expresiones materiales como simbólicas se manifiestan constantemente en el ejercicio del poder como en la producción y reproducción de pautas culturales del ser hombre o mujer. Ante un fenómeno tan complejo planteamos un abordaje que nos permita distanciarnos de la visión dominante que vincula a la violencia de género como aquella que es ejercida únicamente sobre las mujeres y mostrar como el género como relación primaria de poder nos somete a todos.
\end{abstract}

Palabras clave: género, violencia de género, universidad, poder.

Abstract:This paper presents some instances of genderviolence on one of the Benemérita Universidad Autónoma de Puebla (BUAP) campuses. The information gathered in the field has led us to reflect on the processes and mechanisms used by individuals to face, on a daily basis, gender schemas that have been socially apprehended and are expressed in daily college life. This paper is based on the assumption that gender violence is structural and that its multiple concrete and symbolic expressions are constantly manifested in the exercise of power and in the production and reproduction of cultural patterns of being a man or a woman. Confronted with such a complex phenomenon, we propose an approach that allows us to distance ourselves from the dominant view that relates gender violence to the type of violence exercised only on women and to show how we all are subject to gender as a primary power relationship.

Keywords: Gender, gender violence, college, power.

1 El presente trabajo se realizó en el marco del proyecto de investigación "La violencia de género en el campus universitario de la BUAP" financiando por CONACyT. 


\section{Introducción}

Este trabajo tiene como objetivo principal cuestionar la visión que relaciona la violencia de género como aquella violencia ejercida única y exclusivamente hacia las mujeres, además propone como alternativa a este planteamiento un enfoque más amplio y complejo que permita evidenciar el carácter estructural de la violencia a partir de la instauración de un modelo de género dicotómico, asimétrico y jerárquico que exige e impone diversas normatividades a los sujetos sociales. Desde una perspectiva antropológica tratamos de enfatizar la importancia que tiene la institución de educación superior en la reproducción y producción de este modelo dicotómico del género, reflexionamos sobre condicionantes culturales que contribuyen en la delimitación de las relaciones genéricas que establece la sociedad anclada en la norma heterosexual, la cual justifica un orden social jerárquico, de subordinación, discriminación y violencia².

Por lo tanto, tratamos de poner énfasis en la correlación significativa entre los niveles de violencia sistémica y las expresiones de violencia entre pares; para ello esbozamos las relaciones intraescolares desde la lógica disciplinaria como un tipo de poder, una modalidad de ejercerlo que implica un conjunto de instrumentos en diferentes niveles de aplicación, como una "tecnología del poder" tal como lo propone Foucault (2008) que no solo reprime; sino que produce una subjetividad especifica mediante la regulación y el disciplinamiento; es decir mediante el carácter productivo del poder.

Mediante entrevistas informales, observación participante, revisión hemerográfica y bibliográfica se recabo información de diversos estudiantes, profesores y personal administrativo del campus de ciudad universitaria; se dio prioridad a espacios recreativos y de esparcimiento como cafeterías, corredores y plazas que permitieran captar expresiones libres y entre pares etarios sobre la temática por investigar.

En la primera parte del escrito hacemos un breve recorrido por diversas perspectivas analíticas para mostrar los fundamentos teóricos y metodológicos que dieron sustento al enfoque empleado para la elaboración del mismo; en la segunda parte ofrecemos ejemplos de algunas respuestas que la universidad ha implementado en relación con la violencia de género.

\section{Discutir el género}

En la década de los setentas encontramos una preocupación por explicar la subordinación de las mujeres, donde la división entre naturaleza y cultura (Ortner, 1979), público y privado (Rosaldo, 1979) fueron los ejes de análisis que permitieron explicar que el lugar ocupado por las

2 La convención interamericana para prevenir, punir y erradicar la violencia contra la mujer, conocida como "Convención de Belém de Pará", aprobada por la asamblea general de la organización de los Estados americanos de 1994 en su artículo $1^{\circ}$ define a la violencia contra la mujer como "cualquier acto o conducta basada en el género, que cause muerte, daño o sufrimiento físico sexual o psicológico a la mujer, tanto en la esfera pública como en la esfera privada". En el ámbito doméstico, comprende entre otros, estupro, violación, malos tratos, tráfico de mujeres, prostitución forzada, secuestro y asedio sexual en el lugar de trabajo, así como en instituciones educacionales, establecimientos de salud o cualquier otro lugar. 
mujeres en la sociedad, se encontraba asociada con su capacidad reproductiva, es decir, con la maternidad y las actividades que este rol social traía consigo. Antropólogas como Michel Rosaldo, Louise Lamphere, Rayna R. Reiter se propusieron crear una "antropología de las mujeres" para someter a la crítica feminista los modelos androcéntricos de la disciplina; a partir de la recuperación de las voces de las mujeres prestaron especial atención a los dominios y sus actividades; así como a las representaciones simbólicas de la feminidad.

Estas investigadoras consideraban a la mujer como el "sujeto" de sus investigaciones, la mujer con mayúscula, es decir universal, transhistórica y transcultural, con una identidad fija e inamovible y como señala Verena Stolcke "pretendían explicar el escaso protagonismo y valor de la mujer en la sociedad, en donde analizaban los papeles y las diferencias sexuales desde la comparación intercultural típica de la antropología, sin conseguir desprenderse de sus supuestos biológicos etnocéntricos" (Stolcke, 2004, p. 84).

El rechazo al determinismo biológico llevo a las feministas anglosajonas a incorporar la categoría de género para enfatizar el carácter relacional y por lo tanto político de las definiciones normativas de la feminidad y la masculinidad, esta visión buscó cuestionar y desmontar los discursos que partían de la biología para explicar la subordinación de las mujeres, y evidenciaron las relaciones de poder presentes en la configuración de hombres y mujeres en tanto actores sociales.

Gayle Rubin elaboró una discusión desde la antropología respecto a la importancia del género en la diferenciación asimétrica de los sujetos en su artículo: El tráfico de Mujeres. Notas sobre la Economía Política del Sexo en el que refiere que todas las sociedades elaboran un sistema sexo/género al que define como "el conjunto de disposiciones por el que una sociedad transforma la sexualidad biológica en productos de actividad humana y, en el cual se satisfacen esas necesidades humana transformadas" (Rubin, 1996, p. 35). Para la autora la explicación de la opresión de las mujeres es preponderantemente social y política, en consecuencia no habría lugar para una explicación de la desigualdad entre los sexos con base en las características biológicas, innatas o esencialistas.

Esta autora nos permite vislumbrar como el reconocimiento de dos sexos que son convertidos en dos géneros por la cultura, instauran un orden heterosexual que se convierte en hegemónico; en consecuencia tenemos sexualidades y géneros que son periféricos, donde cabe señalar que la constricción de la sexualidad femenina es una constante. Años más tarde (1984) la misma autora nos presenta su trabajo Reflexionando sobre el Sexo. Notas para una teoría radical de la sexualidad, en el que cuestiona su propia propuesta sobre el sistema sexo/género, y explica que estas son dimensiones independientes y que como tales tienen que ser trabajadas de diversa manera "pero aunque el sexo y el género están relacionados, no son la misma cosa y constituyen la base de dos áreas distintas de la práctica social. En contraste con las opiniones expresadas en The Traffic in Women, se afirma que es absolutamente esencial analizar género y sexualidad cuando se desea reflejar con mayor fidelidad sus existencias sociales distintas" 
(Rubin, 1989, p. 54). El replanteamiento que Rubín elabora respecto a la categoría de sistema sexo/género nos permite ver que la identidad de los individuos no es unitaria, esencialista, ni coherente, sino múltiple, inacabada y en contradicción.

Paralelo a estos planteamientos encontramos la propuesta teórica de Joan W. Scott, ella recupera el carácter relacional del género, resalta la importancia de historizar la categoría y articularla con los diversos ámbitos de la vida social; la política, el trabajo, la escuela, la familia, para ello asume al género como elemento constitutivo de las relaciones sociales basada en las diferencias sexuales y también como relaciones primarias significantes de poder, el análisis propuesto por la autora continúa puntualizando la necesidad de establecer la interrelación de cuatro niveles diferentes: en primer lugar las representaciones simbólicas culturales; después, la diversas doctrinas que limitan y contienen la significación de esa simbología; continua con la naturaleza cambiante de las relaciones sexuales binarias, y por último, las identidades subjetivas (Scott, 1996, pp. 289-302).

Esta propuesta sugiere que el género debe redefinirse y reestructurarse, ya que no sería suficiente hacer una historia de las mujeres o exaltar a personajes emblemáticos femeninos, sino que se tendría que rescatar el carácter relacional del género para revelar como la diferencia es transformada en desigualdad a través de diversos procesos sociales que impactan en la conformación de las identidades, es decir, se tendría que conjuntar una visión política y social que comprendiera la clase, la raza y la etnia; la necesidad de integrar otras condiciones sociales dentro de las investigaciones de género obedece a las denuncias de las feministas negras que rompieron con la visión indiferenciada de la identidad y subordinación de las mujeres al demostrar que en el mundo moderno mecanismos políticos e ideológicos moldean las experiencias e identidades de las mujeres de modo simultáneo aunque desigual no solo por el hecho de ser mujeres, sino por su condición de clase y raza, es decir, las desigualdades de género son racializadas y las desigualdades socioraciales son generizadas (Stolcke, 2004, p. 93).

Nuevas propuestas han enriquecido las discusiones en torno al género, las cuales han estado encaminadas principalmente a desesencializar las categorías de hombres/mujeres, masculino/ femenino, una autora fundamental de este enfoque teórico-metodológico es Teresa de Lauretis quien propone abordar a las identidades de género como representación y autorepresentación:

Un posible punto de partida consistiría en pensar al género de acuerdo con la teoría de la sexualidad de Michel Foucault, quien concibe una "tecnología del sexo", y en argumentar que también el género, como representación y autorrepresentación, es producto de diversas tecnologías sociales, como el cine, los discursos institucionalizados, diversas epistemologías y prácticas críticas, así como de las prácticas de la vida cotidiana (De Lauretis, 1991, p. 234).

La autora continúa planteando que el género (al igual que el sexo) no es una propiedad (innata) de los cuerpos ni algo existente desde el origen en los seres humanos, sino que es el conjunto 
de efectos producidos en los cuerpos, los comportamientos y las relaciones sociales por el despliegue de una compleja tecnología política (De Lauretis, 1991, p. 234). Desde esta perspectiva habría que destacar el carácter productivo del poder a través de diversos discursos, prácticas formales e informales, que atraviesan las condiciones sociales de clase, raza, etnia, edad y ocupación en la constitución de la identidad y la subjetividad de los sujetos generizados.

Como colofón de este breve panorama en torno a las concepciones sobre el género, se plantea cerrar con la propuesta de cultura de género que, desde la historia cultural elabora Elsa Muñiz donde articula varios de los planteamientos antes mencionados. Se retoma esta postura, ya que saca al género del ámbito de lo doméstico, de lo privado, del parentesco y lo proyecta como parte de un modelo político de nación, homogeneizador, normalizador, regulador que se centró en la consolidación de representaciones de género, que para el caso de México, fueron identificadas a partir de imágenes como el charro y la china; con lo cual excluía una amplia gama de expresiones identitarias, genéricas, étnicas, de clase, sexuales, que no estuvieron acorde con las exigencias de dichos mandatos. Muñiz plantea que la cultura de género debe ser entendida como:

[...] un concepto histórico que en cada sociedad parte de una división sexual del trabajo originada en las diferencias biológicas de los individuos; que supone un tipo de relaciones interpersonales donde los sujetos -hombres y mujeres- comparten una lógica del poder que vuelven tal relación de supremacía masculina, en asimétrica, jerárquica y dominante en todos los ámbitos de la vida de los sujetos; que genera y reproduce códigos de conducta basados en elaboraciones simbólicas promotoras de las representaciones de lo femenino y lo masculino; que a partir de estos códigos y representaciones rigen las acciones de los sujetos de género, desde su vida sexual hasta su participación política, pasando por su intervención en su vida productiva; en este sentido la cultura de género no es privativa de una de las esferas en las que el liberalismo ha dividido la vida cotidiana de los sujetos, sino que transita del llamado ámbito de lo privado al público sin que existan diferencias en las jerarquías de los papeles que cumplimos hombres y mujeres del mismo modo que se mantienen los referentes simbólicos, ya que no sólo se reproducen sino que se acoplan a las necesidades del poder; es así que forma parte de las redes imaginarias de poder, como una zona liminal en la que se relacionan aspectos nuevos y viejos con pseudocambios y reproducciones de sí mismos, estableciendo la normalidad y definiendo la transgresión. Entendida así la cultura de género, nos permite ubicar la construcción histórica, cultural y social de la diferencia sexual frente al poder todo (Muñiz, 2002, p. 321).

La propuesta de Muñiz parte del argumento de que la discusión en torno al género como categoría explicativa, resulta limitante, en este sentido y con afán de incorporar un enfoque que dé cuenta de múltiples manifestaciones y articulaciones del poder en la vida cotidiana de hombres y mujeres, se desarrolla la categoría cultura de género (Muñiz, 2002). En este sentido 
concordamos con Elsa Muñiz cuando señala que la categoría de género ${ }^{3}$ no permite por si sola avanzar en la elaboración de una nueva periodización histórica o ir más allá de dar cuenta de los acontecimientos o decisiones tomadas desde el poder y que han afectado a las mujeres más que a los hombres en determinados momentos históricos (Muñiz, 2002, p. 319).

Desde la cultura de género tenemos la posibilidad de mostrar las relaciones de poder existentes entre hombres y mujeres, entre las mujeres mismas y desde luego, entre los varones, el análisis de las relaciones inter e intragenéricas, esto nos lleva a sugerir la pertinencia de incorporar a la discusión teórica de la violencia un enfoque de género que muestre las complejas relaciones de poder que sustentan las asimetrías entre los miembros de diferentes culturas y al interior de las mismas, porque no todas las mujeres viven de la misma forma la opresión, ni esa opresión se ejerce únicamente por parte de los varones, también entre las mismas mujeres se someten a procesos de inclusión y exclusión por la condición étnica, la clase social, la edad, la religión, la preferencia sexual y las normatividades de cada cultura. Aunado a esto, también se puede apreciar al género como una relación primaria de poder que influye en la constitución misma de los sujetos.

Con esta breve revisión crítica también hemos querido evidenciar como en las investigaciones de género se ha creado una tendencia a relacionar estrechamente a este último con las mujeres, esto a pesar de las nuevas propuestas teóricas en torno al mismo, (De Lauretis, 1991, Scott 1996, Butler 1999, Rubin 1989, Dorlin 2009, Muñiz 2002) que ha buscado recuperar el carácter relacional del género, para cuestionar la naturalización del ser mujer y articular la condición de género con otras dimensiones de la constitución identitaria de los sujetos. En este sentido consideramos importante subrayar que en el hecho de asumir al género como sinónimo de mujeres se ha posibilitado la identificación de la violencia de género como única y exclusiva contra las mujeres ${ }^{4}$, como un ejercicio de poder de los hombres sobre las mujeres en donde se niega la condición y relevancia de que la violencia de género es una problemática que nos atañe a todos.

En el ámbito de la investigación educativa, la asociación de violencia y género (entendida como sinónimo de mujeres) dificulta el reconocimiento de otras expresiones y agentes de la violencia, como la que se lleva a cabo entre los colegas del mismo sexo, la que ejercen los jóvenes sobre los adultos [...] y también las violencias que afrontan los individuos, ubicados en distintas posi-

3 La "perspectiva de género" de manera general se puede caracterizar por dos cuestiones principales; por un lado, la naturalización y universalización del patriarcado como modo de opresión de las mujeres y por otro que el género es la construcción social de la diferencia sexual, es decir el sexo sería lo natural y el género lo cultural, ante estas limitantes y para tratar de solventarlas, como ya hemos mencionado, es que hemos retomado el concepto de cultura de género.

4 Abogamos por una perspectiva amplia del concepto de género, no pretendemos ignorar que las mujeres en su mayoría son quienes viven violencia; pero consideramos de suma importancia tratar de recuperar las múltiples manifestaciones de un fenómeno tan complejo como la violencia y podamos ir más allá de la diada, mujer-víctima, hombre-victimario, pretendemos no caer en naturalizaciones, ni redificar la diferencia sexual como el elemento primordial estructurante de la relaciones de género. Desde nuestra perspectiva ampliar el análisis abriría la posibilidad de explorar por ejemplo a la discriminación por preferencias sexuales, identidades genéricas, religiosas, adscripciones políticas, etc., pues la discriminación no está ausente de la universidad, ni mucho menos deja de ser violenta; en este sentido no debemos esperar a que sus manifestaciones sean ostensibles para posteriormente atenderlas. 
ciones jerárquicas y en el desempeño de roles diversos, cuando no logra una "correcta actuación de género" (Pereda, Hernández y Gallegos, 2013, pp. 343-344).

Si partimos del hecho de que el género es una relación estructural de poder y que, por lo tanto, genera violencia al estratificar y jerarquizar lo masculino sobre lo femenino, tal como lo plantean Scott (1996), Arisó y Mérida (2010) debe quedar claro que no escapamos a esta relación primaria de poder, a estas clasificaciones y estratificaciones como sujetos generizados; además no se debe perder de vista que este mismo ejercicio de poder enfatiza su carácter productivo en lo referente a la subjetividad de cada uno de nosotros conformándonos como seres intelegibles.

La violencia de género responde a una violencia estructural que en muchas ocasiones ha sido "naturalizada", sobre la lógica de la dominación y las relaciones de poder que edifican nuestra cultura; esta se relaciona con otras categorías construidas ideológicamente que llegan a conformar nuestra identidad o autorepresentación (ficticia o real) en la medida en que conforman nuestras formas de aprehender la realidad, pensar, hablar, vivir (Arisó y Mérida, 2010, p. 10).

Desde esta postura observamos a la universidad como una institución que tiene el poder cultural, no solo para pautar las relaciones entre los géneros, sino que también apoya su construcción y desarrollo diferencial que dictamina comportamientos, justifica conductas y reproduce modelos culturales que están vigentes en la sociedad, contexto social del cual no puede eludirse la institución de educación superior por ser parte del mismo.

\section{Manifestaciones de la violencia en la universidad}

Con relativa frecuencia se considera a la universidad como un espacio donde se reducen dramáticamente las jerarquías entre hombres y mujeres, entre pares y demás personal que integra a la población universitaria, también se cree que las diferencias y desigualdades establecidas por una cultura de género no se ven reflejadas en la cotidianidad de las prácticas mismas de los universitarios; se piensa que por ser el lugar donde se educan a los sujetos, se vuelve un espacio libre de violencia de género; pero debemos decir que no hay nada más alejado de la realidad, el hecho de que no sean tan evidentes las manifestaciones de violencia no quiere decir que no existan; no hay que perder de vista que las pautas culturales que mejor funcionan en la sociedad, son precisamente aquellas que no permiten observar sus orígenes como procedimientos y en consecuencia se tienden a naturalizar comportamientos y creencias de las cuales por cierto no escapa la población universitaria.

En este sentido resulta necesario analizar la aparente neutralidad, naturalidad y universalidad en la que se constituyen los sujetos universitarios de la ciudad de Puebla, así como las reacciones que la Benemérita Universidad Autónoma de Puebla (BUAP) implementa como políticas en torno a la violencia de género. Es común que en los estudios sobre la violencia en espacios edu- 
cativos no se problematice el contexto institucional ${ }^{5}$, con esto se manifiesta que pocas veces se asume que haya prácticas violentas (legitimadas, naturalizadas, culturalmente aceptadas) que constituyen una parte inherente de la propia escuela y que las maneras de actuar de los sistemas escolares y sus estrategias que de todos modos ejercen coerción y violencia al interior de la misma, tal como apunta Roberto González Villarreal "la escuela nunca ha sido y probablemente nunca sea, un espacio libre de violencia” (González, 2009).

No queremos caer en contradicciones "naturalizando" a la universidad como un espacio violento, lo que pretendemos señalar es que con frecuencia se asumen como un mal necesario o justifica el orden que impone la institución educativa, con el afán de conseguir mejores condiciones para la enseñanza, mayor aprovechamiento escolar, excelencia académica, etc., estrategias para la integración de los universitarios en formas que se nombran como armoniosas y civilizadas y que forman parte de un contexto político más amplio que el de la universidad ${ }^{6}$.

En la medida en que la escuela no es una institución aislada y desconectada de las estructuras sociales más amplias; ni tiene autonomía respecto de las formas organizativas de la vida asociada en que se inscribe; ni es ajena al tipo de relaciones de producción y reproducción en que opera y a que contribuye, las interacciones intraescolares transparentan y replican las formas de la violencia que corresponden a las desigualdades de clase, a las inequidades distributivas de los bienes y el poder, a las disparidades de estatus entre los diversos actores sociales (Salmerón, 2012, p. 375).

Por consiguiente es importante subrayar que la universidad forma parte de un entramado social del cual no puede excluirse totalmente y que como dispositivo de poder y espacio de socialización política ha redoblado esfuerzos por optimizar el funcionamiento de los postulados que exigen comportamientos e ideologías ${ }^{7}$ del ser hombre o mujer como universitarios o bien

Dos tipos de acercamientos sobre la violencia parecen distinguirse con claridad, por un lado aquellos que utilizan el término violencia escolar para dar cuenta de las prácticas de agravio que ocurren en la escuela como producto de las condiciones estructurales del grupo social más amplio en que la institución se encuentra; y por otro el de violencia en la escuela para enfatizar los componentes de la agresividad que se presentan en las relaciones horizontales entre pares dentro del contexto escolar.

6 Estamos hablando de factores históricos, políticos y económicos tales como las reformas universitarias de finales de los 80 en México, de las crisis económica y política, de los procesos electorales y el cambio que implicó la supresión del Estado de bienestar por uno neoliberal, todo esto como parte de una misma época, de un contexto social e histórico que marcó nuevos parámetros de los roles que debían cumplir las instituciones de educación superior, sus docentes, personal administrativo así como sus estudiantes. Las reformas grosso modo apuntaron al reordenamiento y financiamiento de las universidades públicas mediante planeación y evaluación de estas instituciones. Profesionalización de los académicos y un fuerte engrosamiento del personal administrativo. En los años 90 el discurso gubernamental cambió del interés en la equidad, accesibilidad, autonomía o la contribución de la educación superior a la transformación social, hacia el interés acerca de la excelencia académica, eficiencia, gastos y tasas de reingreso. Sería hasta finales de los 90 y principios de la década de los años 2000 que la equidad de género aparecería en los discursos institucionales de la BUAP. Por su lado la actual administración ha planteado su propia política aprobada por el Consejo Universitario para el periodo 2009-2013 y en ese contexto se creó el Modelo de Equidad de Género dirigido y conformado por autoridades de primer nivel de la institución.

7 La BUAP se compromete a establecer y promover un clima organizacional saludable, libre de violencia, garantizando la igualdad de trato y oportunidades entre mujeres y hombres, proviniendo y eliminando cualquier tipo de discriminación y hostigamiento, a través de acciones de responsabilidad social para conciliar la vida laboral con la vida personal y familiar con el propósito de brindar a la comunidad universitaria y sociedad en general, la seguridad y confianza de ser una institución comprometida con la defensa de los derechos humanos y la equidad (Modelo de Equidad de género de la BUAP). 
como futuros profesionistas, en consecuencia tampoco es ajena a las formas de producción y reproducción del género, del poder y la violencia.

Las dinámicas de la universidad relacionadas con la violencia de género responden a ámbitos sociales muy diversos, tanto que por ello tratamos de delimitar nuestro enfoque a espacios poblacionales representativos de la institución que permitan observar las formas a través de las cuales se está viviendo y manifestando la violencia en las relaciones entre pares como entre docentes y alumnos, pues la investigación se centró en captar las expresiones que permiten la reproducción de un orden social jerárquico y violeto al interior de la casa de estudios; a través de tres ejemplos mostramos algunas reflexiones que nos parecen pertinentes en relación con las expresiones visibles de la violencia en el ámbito educativo.

\section{La agresión física entre pares de la universidad}

Aunque no suelen ser comunes, se presentan casos donde los universitarios hombres y mujeres, efectúan agresiones físicas entre ellos, esto puede darse en los salones como en las áreas recreativas. Los motivos son diversos y pueden ir desde la falta de respeto a las diferencias de opiniones, hasta los conflictos amorosos, que incluyen descalificaciones o rumores sobre las personas, por mencionar algunos.

No conocí la causa del porque se pelearon, pero bueno al momento en el que se agarraron del cabello, todos no sabían nada que hacer, hasta la profesora no sabía cómo reaccionar, se quedó sentada, se quedó en shock y todos los demás en el salón nada más viendo. Yo desde el otro lado del salón me metí y las separé, yo también me llevé un golpe de las niñas, pero pues ya que. Esa es la experiencia que yo he tenido ${ }^{8}$.

Queda claro que profesores y alumnos no saben cómo actuar ante contingencias como las recién expresadas; no hay protocolos de respuesta; pero quizá lo más preocupante es que no se sabe a qué instancia dentro de la universidad se debe acudir para intentar solucionar una situación tan delicada como la expuesta. Por lo general, se busca con arreglos informales entre las partes involucradas, dar solución y sobre todo dejar pasar atrás el problema, y así esperar a que se olvide y no se vuelva a presentar.

En este contexto, en la detonación de agresiones entre varones, las concepciones de género juegan un papel importante. Las clasificaciones de puto, maricón o gay son las más comunes entre los estudiantes universitarios y al mismo tiempo resultan ser desviaciones funcionales; pues jerarquizan las relaciones sociales y se vuelven el medio por el cual los varones afirman su género normativo y lo niegan en ese otro; no importando cuál de las tres categorías sean

8 Estudiante de Gastronomía, comunicación personal, 13 de noviembre 2014. 
empleadas, también, se engloban a las diversidades en el saco de la diferencia. En este sentido los estudiantes heterosexuales masculinos son sospechosos de ser maricas, putos o gays, hasta que se demuestre lo contrario y es en el proceso de cortejo, entendido como prácticas rituales de las relaciones afectivas, donde se pueden apreciar las diferencias que darán base a las clasificaciones y exclusiones; pues el varón con déficit de hombría es asignado al género femenino tal como lo apunta Oscar Guasch:

Es marica quien no cumple con las normas y expectativas de género previstas para los hombres, y esto sucede al margen de sus preferencias y gustos sexuales [...] la etiqueta de marica amenaza a todos los varones por igual y les impulsa a adecuarse a las normas de género [...] un hombre de verdad jamás admite ser tratado como mujer (Guasch, 2006, p.124).

La analogía que se establece entre el marica y la mujer refleja concepciones socioculturales que permiten observar en acción tanto al sexismo como a la homofobia; pues en sentido estricto ningún hombre que se precie de serlo o busque serlo aceptará la comparación con las mujeres, con seres inferiores, subordinados y penetrables. La diferencia en la que engloban al marica no deja de ser identificada como desigual, esto de manera general justifica los comportamientos violentos con todo aquel que se salga de la norma. En este sentido la clasificación de marica entre los universitarios se adecua al modelo dicotómico del género, lo reproduce y se podría decir que refuerza las prácticas como las jerarquías sociales que se manejan entre los estudiantes mismos.

En un partido de futbol entre compañeros de la facultad se empezaron a calentar los ánimos y pues dos chavos se prendieron y la pelea comenzó cuando uno de ellos le dijo al otro chavo pinche maricón, eres puto y no te avientas y que se agarran a golpes, ya después los separamos, pero esas peleas pasan seguido en los partidos ${ }^{9}$.

\section{La discriminación del docente hacia los alumnos}

Las relaciones entre docentes y alumnos suelen estar marcadas por cierta autoridad que ostenta el profesor desde la cual genera un trato jerárquico hacia sus estudiantes ante tal situación estos últimos suelen justificar a través de frases tales como "son sus formas de ser", "es su sentido del humor", las relaciones asimétricas de las cuales forman parte. Por otro lado, las posibles respuestas de los universitarios hacia sus maestros suelen manifestarse a través de los apodos, las burlas y omisiones, estas prácticas llegan a ser consideradas por los mismos alumnos como una manera de resistencia. En ambos casos podemos decir que tales posturas comparten un elemento en común, el ejercicio implícito de violentar a un sujeto de acuerdo con la situación estratégica en la que se vean involucrados.

$9 \quad$ Estudiante de Ciencias Políticas, comunicación personal, 23 de marzo del 2015. 
Si hay profesoras por ejemplo que son como homofóbicas, hay una profesora que, hay un compañero que es gay y le hace ese tipo de comentarios, jay! qué bonita está tu ropa mi rey, remarcándolo cuando no es necesario [...] Esa misma profesora discriminó a un compañero oriental que venía de intercambio, porque ni siquiera lo llamaba por su nombre, le decía ja ver tú chino!, lo trataba muy mal en frente de todos y al final el chavo terminó desertando de la clase ${ }^{10}$.

Las relaciones de poder presentes en el ámbito universitario se tienden a naturalizar, justificar e interiorizar, la desigualdad de situaciones con base en el poder otorgado a cada una de las figuras que integran la población universitaria se manifiestan principalmente entre docentes y alumnos esto de ninguna manera exonera las relaciones que mantienen los estudiantes con el personal administrativo, de mantenimiento y de seguridad en el interior de la casa de estudios.

Como parte de esta interiorización de discursos que refuerzan estereotipos de género que son fomentados desde el ámbito institucional nos encontramos que en periodo de exámenes en algunas facultades como la de Administración, Contaduría, Derecho principalmente a los estudiantes se les pide que vayan "presentables", lo que implica para las mujeres ir de pantalón o falda, zapatillas y saco, para los hombres los requisitos son pantalón de vestir, camisa, y saco, solo algunos profesores piden corbata (en Derecho la corbata es obligatoria). Los(as) profesores(as) señalan que solicitar esta vestimenta a los(as) estudiantes se encuentra relacionada con su futuro profesional, que se vayan adaptando a los requerimientos que el mercado laboral les hará cuando busquen empleo, afirman que la sociedad es así y que ¡cómo te ven, te tratan!

Aquí te piden algunos maestros que vengas formal en una presentación, en una exposición o en exámenes, pero no es que te obliguen es por mero formalismo, luego hasta es por iniciativa propia. De por si esta facultad es muy visual, si los ves no andan tan desalineados, no somos fachosos, nos importa la imagen entonces ${ }^{11}$.

Observamos como estos discursos son interiorizados por las estudiantes, los asumen como parte de su identidad profesional y se encuentran con ellos en escenarios cotidianos dentro de la universidad tales como las imágenes que decoran los sanitarios de la facultad de administración; en estas siluetas podemos ver condensados modelos de belleza asociados a la feminidad y la masculinidad que para muchos jóvenes pueden ser inalcanzables y se sienten excluidos al no encarnar tales iconografías idealizadas, podríamos estar ante una violencia corporal fomentada desde y por la institución.

\section{Discriminación por clase social}

Una de las formas más comunes en la que se manifiesta la violencia entre pares en la universidad gira en torno al clasismo. Hay jóvenes para quienes resulta muy importante hacer uso ostentoso

$10 \quad$ Estudiante de Comercio Internacional, comunicación personal, 11 de febrero 2015.

11 Estudiante de Gastronomía, comunicación personal, 11 de noviembre del 2014. 
de artículos de diversas marcas comerciales que estén de moda y con base en estos generar diferenciaciones con sus compañeros de estudios; el poder adquisitivo resulta determinante en este tipo de relaciones y los objetos pueden ir desde la marca de la ropa hasta tener automóvil.

Es muy común en esta facultad la discriminación por clase social o por cómo te vistes y cosas así, se hacen mucho los grupos cada quien se junta con quienes se identifica y ya hay otros que no entran en ciertos grupos... estos grupos se organizan por las cosas materiales que tengas, porque si no tienes el nuevo celular o cosas así no tienes de que platicar, si no tienes cierta cosa no perteneces a ese grupo ${ }^{12}$.

En esta universidad de carácter público encontramos que la clase social es una condicionante para tomar en cuenta en los procesos de segregación entre pares y diversos miembros de la institución, lo que hace evidente un vínculo entre violencia y discriminación. Estas dinámicas también conllevan actitudes de autoexclusión por parte de los estudiantes y se aíslan de múltiples actividades que se desarrollan en este ámbito educativo.

A partir del trabajo de campo y posteriormente mediante las entrevistas pudimos identificar las cafeterías como espacios de sociabilidad donde se ponen en evidencia las diferencias de clase, entendidas por los universitarios como poder adquisitivo, en algunas se generan una especie de apropiación por cierto sector estudiantil al que se refieren con los calificativos de "los juniors" y "los hijos de papi", "los que no entran a clases y pasan las materias". Son en estas áreas donde comúnmente los estudiantes viven o ejercen prácticas discriminatorias, diversos grupos se apropian de las mesas que ahí se encuentran y las burlas entre ellos o lanzadas hacia algún otro son actos recurrentes. Es en estos espacios donde se puede escuchar a las jóvenes hablando de los "antros", las marcas de ropa mientras algunas se maquillan o muestran los accesorios que llevan puestos; por su lado los varones hablan de deportes, juegan baraja, póker y de "chavas". Este espacio fue identificado por los mismos estudiantes como el segundo lugar donde más se llevan a cabo actos discriminatorios, el primero lo ocupan las aulas ${ }^{13}$.

En este contexto las prácticas de discriminación que se visibilizan mediante críticas y/o burlas se dirigen a la apariencia física (complexión robusta y color de piel principalmente), vestimenta y accesorios (bolsas, zapatos, aretes, collares) y aparatos tecnológicos (smartphone y laptops) que portan los sujetos. Dichos aspectos se interrelacionan para generar procesos de inclusión y exclusión difíciles de identificar por nosotros como por los estudiantes dada la naturalización y normalización que se hace de la violencia de género asociada a la discriminación.

12 Estudiante de Administración Turística, comunicación personal, 2 de diciembre 2014

13 Estás áreas fuera de los salones de clase se eligieron para realizar trabajo de campo, ya que nos interesaba dar cuenta de expresiones de la violencia más allá de las relaciones jerárquicas profesor/estudiante. 
Hay compañeros que porque yo me visto así, con mezclilla, mis camisas de cuadros, mis botas, me ven raro. Yo vengo a estudiar y no soy ningún hijo de papi y pues para mí no es importante eso de las apariencias, pero hay compañeros que por eso se quieren burlar de ti y pues aunque luego pues si es molesto trato de que no me importe, yo vengo a estudiar ${ }^{14}$.

\section{La feminización de la matrícula ${ }^{15}$}

La equidad vista como la igualdad de acceso a oportunidades de educación superior entre hombres y mujeres no ha permitido observar que la presencia mayoritaria de las mujeres en una carrera no se refleja en un cambio en las concepciones de género, es más, en estos escenarios se dan una reproducción de los ideales, normas, conductas y valores asociados con la feminidad como señala Adrián de Garay para el caso de carreras feminizadas "son identificadas social y culturalmente con aspectos relacionados con la vida privada de los sujetos, y que se ha atribuido tradicionalmente al "ser"y al “hacer" femeninos" (De Garay, 2011, p. 11).

Otro fenómeno que caracteriza el desarrollo reciente de nuestro sistema educativo a nivel superior es la creciente incorporación de mujeres, lo que algunos han llamado la feminización de la matrícula universitaria. Mientras que en 1970 solamente el 24 por ciento de la matrícula nacional estaba conformada por mujeres, para el 2004 ascendía al 49 por ciento (De Garay, 2008, p. 208).

Resultado de la integración de las mujeres en la educación superior y la participación de estas en el mercado laboral, los espacios que se crearon para ellas estuvieron relacionados con la prestación de servicios como la enseñanza, la enfermería y el trabajo social; actualmente podríamos añadir turismo, gastronomía, contaduría, administración entre otras, profesiones que se diferencian de aquellas con mayor prestigio destinadas a los hombres tales como la ingeniería, el derecho y la investigación científica (Conway, Bourque y Scott, 1996, p. 25).

Con la creciente presencia de mujeres en el sistema educativo superior, se cree que de manera automática se cambia el ambiente escolar y cultural en el interior de las instituciones, como si el simple acceso a dichos espacios, volviera a estas instituciones más equitativas; es decir a la universidad se le reconocería como un espacio con "equidad de género", de asumirlo así, parece que se nulificaría a las universidades como instituciones sociales productoras y reproductoras de relaciones de género preexistentes en la sociedad. Además, dicho discurso de "equidad de género", sigue circunscrito al paradigma distributivo de la justicia social y para que este funcione presupone la existencia de un marco democrático donde hombres y mujeres tienen, solo en teoría, las mismas oportunidades.

$14 \quad$ (Estudiante Ciencias Políticas, comunicación personal, 19 de febrero 2015).

15 Se debe señalar que al fenómeno social de la participación de las mujeres en los ámbitos de la educación superior se le ha llamado, "feminización de la matricula"y que por los objetivos del artículo no se somete a revisión profunda tal propuesta conceptual. Se utiliza únicamente como un ejemplo de las dinámicas sociales que las instituciones educativas como la BUAP ponen en marcha para justificar la existencia de una equidad de género, una repartición material de la justicia social entre la población estudiantil. 
El paradigma distributivo define la justicia social como la distribución moralmente correcta de beneficios y cargas sociales entre los miembros de la sociedad. Los más importantes de estos beneficios son la riqueza, el ingreso y otros recursos materiales. La definición distributiva de la justicia a menudo incluye, sin embargo, bienes sociales no materiales tales como derechos, oportunidades, poder y autoestima (Young, 2000, p. 33).

Si la equidad de género persigue un tipo de igualdad entre hombres y mujeres; no solo en espacios y oportunidades de trabajo o como en este caso de educación; sino también un cambio en las relaciones sociales de los universitarios, nos parece que esta "repartición material" de los espacios educativos, administrativos, académicos, etc., no favorecería dicha igualdad aunque las mujeres tuvieran una presencia numérica más amplia en la universidad. A lo anterior debemos añadir que los elementos discursivos de tal equidad, en muchas ocasiones, son producidos por los requerimientos políticos de distintas evaluaciones a las que son sometidas y de las cuales buscan su certificación, solo bajo esta lógica cobran sentido espacios diseñados exclusivamente para las mujeres como "el espacio para la mujer" o "el gimnasio al aire libre" que no solo suelen estar vacíos y que siguen generando segregación hacia las mujeres.

Encuentro en este paradigma distributivo dos problemas [...] primero, dicho paradigma tiende a ignorar el contexto institucional que determina la distribución material, al mismo tiempo que con frecuencia lo presupone. Segundo, cuando el paradigma se aplica a bienes y recursos no materiales la lógica de la distribución los tergiversa (Young, 2000, p. 36).

La disposición numérica de una distribución de empleos en áreas administrativas, académicas, espacios de gobierno, como docentes demuestran las problemáticas que implican los postulados que dan sustento a dicha propuesta de la repartición material de la justicia, tal parece que la lógica del 50-50 no trae consigo una equidad de género entre hombres y mujeres y mucho menos desaparece los tipos de violencia entre los mismos sujetos al momento de estabilizar concepciones de género dicotómicos y desde luego normativos que parten de la diferencia para transformarla en desigualdad.

\section{La equidad de género certificada}

El Instituto Nacional de las Mujeres (INMUJERES) produjo su Modelo de Equidad de Género (MEG) en el $2003^{16}$, como un sistema de gestión con perspectiva de género y su correspondiente certificación a

16 El instituto Nacional de las mujeres (INMUJERES) en el año 2003 produjo su Modelo de Equidad de Género (MEG), un sistema de gestión con perspectiva de género, que buscaba desde entonces proporcionar herramientas a las empresas, las instituciones públicas y las organizaciones sociales para asumir un compromiso con la igualdad entre mujeres y hombres en los centros de trabajo, para ello el programa contempló la certificación en equidad de género, con tal reconocimiento instituciones y empresas tanto públicas, así como de la iniciativa privada han podido demostrar su compromiso con la igualdad de oportunidades para mujeres y hombres dentro del mercado laboral. 
instituciones públicas como privadas. La BUAP buscó dicha certificación y con el paso del tiempo ha llegado a proponer su Modelo de Equidad de Género $(\mathrm{MEG})^{17}$ como política interna de la universidad.

Sin embargo, parece que dichas propuestas siguen bajo una perspectiva tal que refuerza la naturalización de los sujetos como única justificante de lo que resulta inmutable y legítimo del orden social existente, por lo menos así lo dejó ver el juego de palabras empleado por el rector de la BUAP en el 2012, tras haber conseguido la certificación por parte del INMUJERES.

Lo hermoso de esto es que ha sido natural porque así lo pensamos y porque así lo sentimos, nos sentimos compañeros y cómplices en el propósito de servir a esta Universidad, mujeres y hombres somos cómplices de los logros de esta Institución y juntos podemos sentirnos orgullosos de lo que hemos hecho ${ }^{18}$.

Los movimientos feministas y los posteriores estudios del género y sexualidad enfatizaron la importancia de la desnaturalización de las diferencias sexuales y genéricas, de clase, étnicas, etc., los cuales cuestionan precisamente el papel que los discursos universales y esencialistas han creado al ratificar las normas existentes en la sociedad, por ello resulta interesante cómo el entonces representante de la universidad, apeló a la naturaleza para volver legítimo y sólido el discurso de equidad de género propuesto por parte de la institución educativa; pero debemos observar que los discursos del género están montados en una normatividad, dentro de una lógica del poder que nada tienen de naturales.

Por su lado, la actual administración ha planteado su propia política aprobada por el Consejo Universitario para el periodo 2009-2013 y en ese contexto se creó el Modelo de Equidad de Género (MEG) dirigido y conformado por autoridades de primer nivel de la institución, algunos de los objetivos sobre los cuales ha sido formulado dicho modelo de la BUAP son dar orientación acerca del procedimiento para la atención de denuncias sobre discriminación, hostigamiento y acoso sexual en la universidad, sin embargo, aún resulta incierta la dimensión del problema y las formas particulares que adquiere, al considerar que en muchas ocasiones para las(os) implicadas(os) resulta difícil identificarla y más aún denunciarla. La universidad a través del MEG ha implementado tres tipos de acciones que actualmente se llevan a cabo en la BUAP y son las siguientes:

[...] primero la "Creación de espacios universitarios por la Equidad de Género", con el objetivo de dar una amplia difusión a temas como los derechos de la mujer, equidad de género, e igualdad de oportunidades. Cabe destacar que estos espacios -físicos-cuentan

En el Hospital Universitario de la BUAP se obtuvo la certificación y distintivo en el 2009. De acuerdo con declaraciones de José lgnacio Rojas González, titular de la Dirección de Desarrollo Sustentable Institucional (DIDESI), debido al compromiso de la BUAP por adoptar este modelo y practicarlo, se ha implementado un plan de acción, que integra a 56 dependencias universitarias, entre las que se encuentran: 9 unidades regionales, 3 escuelas profesionales, el nivel medio superior, 20 facultades, 4 institutos y 19 dependencias administrativas, encabezadas por la rectoría. Este número ubicaría a la institución como la única en contar con un número tan elevado de certificaciones de este modelo en Puebla y el país, todo ello respaldado por un sistema de mejora continua, basado en el respeto, equidad e igualdad de oportunidades en el centro laboral.

18 La declaración fue realizada por el rector Enrique Agüera Ibáñez, obtenida en este sitio de información en línea. BUAP recibió certificación del Modelo de Equidad de Género. http://pueblaonline.com.mx/index.php?option=com_k2\&view=item\&id=3109. 
con una amplia colección de libros, revistas y periódicos que están al alcance de la comunidad universitaria para su consulta [...] El segundo es "Universitarios por la equidad de Género", a partir de la cual se busca sensibilizar y generar conciencia de igualdad de género y reconocimiento de las aportaciones de mujeres a la cultura y a la historia. Además de sensibilizar a la población universitaria, académica y administrativa, sobre temas como la igualdad de oportunidades, problemas de salud pública e igualdad entre mujeres y hombres. [...] Un tercer proyecto; se están llevando a cabo "Campañas de Salud" sobre métodos anticonceptivos y detección oportuna de $\mathrm{VIH}$; y la realización de diversos foros sobre sexualidad, el cual en su primera versión contó con la participación de más de 400 asistentes universitarios quienes pudieron interactuar con los ponentes especialistas sobre temas como la identidad sexual, el uso correcto de anticonceptivos, la importancia de la comunicación en pareja y los derechos sexuales (Gómez, 2014).

En este trabajo no se pretende someter a evaluación las acciones correspondientes al MEG de la BUAP; sin embargo podemos esbozar algunas de las características de estos programas institucionales al afrontar a un fenómeno complejo como la violencia de género; da la impresión de que la institución parte de identificar a las mujeres como las víctimas de dicha violencia al generar espacios exclusivos para las mismas; esto se contradice con la segunda acción que busca establecer una equidad entre los universitarios; valdría la pena preguntarse cómo se lograría la equidad de género o cómo se podría prevenir la violencia mediante la segregación de las mujeres. Esto nuevamente remite a la repartición material de la justicia social antes mencionada. Las acciones de manera general están enfocadas a atender a la comunidad universitaria.

Desde luego el trabajo en torno al género no es nuevo en la BUAP, se ha tratado de hacer mucho al interior de la institución desde diversas facultades y cuerpos académicos, los cuales han buscado impactar de manera positiva entre la población universitaria, aquí no se pretende hacer una recuento de estas, ni una cronología de las mismas; sino más bien apuntar algunas ideas que resultan conflictivas para la cotidianidad de los universitarios por ejemplo no queda del todo claro cómo la certificación generará relaciones sociales equitativas en todos los integrantes de la comunidad universitaria; pues cabe mencionar que la certificación atañe principalmente al ámbito laboral de la institución y que a dicha certificación también subyace, una concepción de repartición material de la justicia, distributivo o numérico.

\section{Reflexiones finales}

Se ha planteado la necesidad de ampliar la mirada sobre la violencia de género a partir de retomar elementos teóricos y metodológicos que contribuyan a desnaturalizar prácticas y desescencializar a los sujetos que las ejercen, en otras palabras discutir al género. De igual manera se considera necesario reflexionar a la violencia de género más allá de la relación diádica hombre/ agresor-mujer/violentada que se ha planteado tradicionalmente desde las acciones y estra- 
tegias que buscan afrontarla y en este sentido evidenciar que no es igual a violencia contra las mujeres, ya que se estaría reforzando una relación esencialista de subordinación, de ahí la pertinencia de ver al género como una representación que se despliega a través de diversos discursos que intervienen de manera determinante en la constitución de individuos históricos concretos en hombres y mujeres.

Se asume que la violencia de género es estructural y que sus manifestaciones físicas, psicológicas como simbólicas se encuentran ancladas en lo que podríamos denominar la normatividad del género, misma que subordina a lo femenino ante lo masculino y que a través de la violencia (sutil u hostil) tiende a mantener un orden social hegemónico masculino y heterosexual que excluye y castiga a hombres y mujeres que no respondan a las exigencias que dicha normatividad impone; ante esta realidad es necesario implementar una concepción sobre la violencia de género que no sea exclusiva de las mujeres. Con ello se abriría la posibilidad de explorar a la discriminación por preferencias sexuales, identidades genéricas, religiosas, adscripciones políticas, clase social, etc., discriminación que no está ausente en la universidad, ni deja de ser violenta.

Además, interesa enfatizar en la dificultad que implica seguir entendiendo a la equidad de género desde la postura distributiva de la justicia social, puesto que con bienes no materiales tales como derechos, oportunidades, poder y autoestima por mencionar algunos ejemplos, tal lógica se vuelve limitante; precisamente al no considerar que los factores culturales y los cambios dentro de este ámbito no son rápidos ni mecánicos y que dependen de múltiples factores sociales. Si bien dichos planteamientos han sido un buen intento que ha buscado fomentar precisamente la igualdad entre hombres y mujeres; desde la perspectiva aquí propuesta, se debe seguir buscando y problematizando precisamente los postulados que dirigen tanto las tomas de decisiones como las implementaciones en la cotidianidad de la vida universitaria.

Se trató de demostrar que la institución de educación superior no es un aparato desconectado del mundo en el que opera y el cual, por cierto, contribuye a conservar y reproducir. Por lo tanto, es pertinente señalar que la escolaridad cuenta con instrumentos teóricos y prácticos que le permitirían deslindarse de algunas condiciones del entorno, como la violencia de género; por la peculiaridad de sus funciones su presencia y alcance en sus actores podría ser un factor positivo que marque la diferencia en la creación de nuevos ambientes y relaciones sociales alternativas al resto social. Al respecto Ana María Salmerón dice lo siguiente:

Como ninguna otra institución, la escolar tiene el poder de generar y promover nuevos y distintos hábitos de pensamiento y conductas reconstruidas que se orienten a la superación de las condiciones fácticas (Salmeron, 2012, p. 395).

Asimismo, queda claro que la encrucijada es compleja; sin embargo no hay que perder de vista que la educación como actividad, tiene la capacidad de modelar disposiciones, de promover 
formas de pensamiento y redirigir acciones. La discusión no está cerrada y se apuesta por el establecimiento de un diálogo que lo enriquezca y permita integrar nuevos elementos o profundizar los ya planteados.

\section{Referencias}

Benemérita Universidad Autónoma de Puebla (n.d.). Facultad de administración. Recuperado de: http://www.administracion.buap.mx/.

Benemérita Universidad Autónoma de Puebla (n.d.). Modelo de equidad de género BUAP. Recuperado de: $\underline{\text { http://www.equidadgenero.buap.mx/. }}$

Butler, J. (1999). El género en disputa. El feminismo y la subversión de la identidad, Barcelona: PAIDÓS.

Castro, R. y Vázquez, V. (2008). La Universidad como espacio de reproducción de la violencia de género. Un estudio de caso en la Universidad Autónoma Chapingo, México. Estudios Sociológicos, XXVI(78) 587-616. Recuperado de http://www.redalyc.org/articulo.oa?id=59811148003.

Conway, Burque y Scott. (1996). El Concepto de Género, en M. Lamas (comp.): El género: la construcción cultural de la diferencia sexual (pp. 21-34). México D.F.: Universidad Nacional Autónoma de México-Programa Universitario de Estudios de Género/Miguel Ángel Porrúa.

De Garay, A., Del Valle Díaz, G. (2012). Una mirada a la presencia de las mujeres en la educación superior en México. Revista Iberoamericana De Educación Superior, 3(6). Recuperado de: http://ries.universia.net/article/view/71.

De Lauretis, T (1991) Las tecnologías del género en Ramos,C. (comp) en El género en perspectiva de la dominación universal a la representación múltiple, UAM-I, México, pp. 231-278.

De Lauretis, T. (1991). Tecnologías del género en Ramos, C. (comp.), El género en perspectiva. De la dominación universal a la representación múltiple, pp. 231 - 278. México: UAM- Iztapalapa.

De Vries, W. (2001). "Gobernabilidad, cambio organizacional y políticas", en Revista de Educación superior en línea. No. 118. BUAP.

Dussel, I. (2012). "La disciplina y el poder en la escuela: una lectura desde Foucault". En Furlan Alfredo (Coord.) Reflexiones sobre la violencia en las escuelas. Edit. Siglo XXI, México, pp. 144-176.

Foucault, M. (2000). Defender la sociedad, Argentina: Fondo de cultura Económica.

Foucault, M. (2002). Historia de la sexualidad.1 La voluntad del saber (29a ed.). México: Siglo XXI. 
Foucault, M. (2008). Vigilar y castigar. Nacimiento de la prisión (35ª ed.). México: Siglo XXI.

Gayle, R. (1996). El tráfico de mujeres: notas sobre la "economía política" del sexo. En M. Lamas (comp.), El género: la construcción cultural de la diferencia sexual (pp. 35 -96). México: Miguel Ángel Porrúa/Programa Universitario de Estudios de Género-UNAM.

Gayle, R. (1989). Reflexionando sobre el sexo. Notas para una teoría radical de la sexualidad. En C. Vance (comp.), Placery peligro. Explorando la sexualidad femenina (1-59). Madrid: Editorial Revolución.

Gómez, María., Aguirre, O., y Ramírez, K. (2007). El surgimiento del modelo de equidad de género de la benemérita universidad autónoma de Puebla. En Revista Iberoamericana de Producción Académica y Gestión Educativa.

Guzmán, C. (2012). "La Violencia escolar desde la perspectiva de Francoise dubet: tensiones, reticencias y propuestas". En Furlan, A. (Coord.) Reflexiones sobre la violencia en las escuelas. Edit. Siglo XXI, México, pp. 49-71

Gvirtz, S. y Larrondo, M. (2012). "Democracia, diálogo, construcción de la ley. Caminos para construir la convivencia en el espacio escolar y generar modos no violentos de relación". En Furlan, A. (Coord.) Reflexiones sobre la violencia en las escuelas. Edit. Siglo XXI, México, pp. 295 -312.

Herrera, M. (2008). La categoría de género y la violencia contra las mujeres. En: Aponte, E. y Femenias, L. (Comp.). Articulaciones sobre la violencia contra las mujeres (pp. 55 - 73). Buenos Aires, Argentina: Editorial de la Universidad de la Plata.

Huacuz, M. (2010). "La violencia contra las mujeres. Un problema complejo en el ámbito educativo". En Decisión. Saberes para la acción en la educación de adultos. CREFAL, No.27 sep.- dic. http://tumbi.crefal.edu.mx/decisio/images/pdf/decisio 27/decisio27 saber1.pdf.

Muñiz, E. (2002). Cuerpo, representación y poder: México en los albores de la reconstrucción nacional. México: UAM-Azcapotzalco.

Ortner, S. (1979). ¿Es la mujer con respecto al hombre lo que la naturaleza con respecto a la cultura?. En Harris, O., y Young, K. (compiladoras). Antropología y feminismo (pp. 109-131.). Barcelona: editorial Anagrama. Recuperado de: www.cholonautas.edu.pe/modulo/upload/Ortner\%20S.pdf.

Pereda, A., Hernández, M., y Gallegos, M. (2013). El Estado del conocimiento de la investigación sobre violencia de género y violencia en contra de las mujeres en el ámbito educativo. En Furlán, A., y Spitzer, T. (coord.). Convivencia, disciplina y violencia en las escuelas 20022011 (pp. 333 - 379). México: ANUIES/COMIE. 
Puebla On line (n.d). BUAP recibió certificación de Modelo de Equidad de Género. Puebla On line. Recuperado de: http://pueblaonline.com.mx/index.php?option=com_k2\&view=item\&id=31090:buap-recibi\%C3\%B3-certificaci\%C3\%B3n-del-modelo-de-equidad-deg\%C3\%A9nero\&ltemid $=155$

Rivera, E. (2008). De la crisis a la modernidad de la universidad (1987-1997). La transformación del trabajo académico, una reflexión desde el género, en Fonseca A., Cruz A., Soto G. (Edit.) Diálogos Revista Electrónica de Historia ISSN 1409-469X. Número especial., pp- 2044-3065.

Rodríguez, R. (1999). Género y políticas de educación superior en México. UNAM. La ventana No. 10 pp. 124-159. http://works.bepress.com/roberto rodriguez/14

Salmerón, A. (2012). Notas para una reflexión en torno a la violencia horizontal en las escuelas. Entre el conservadurismo y la intolerancia. En Furlán, A. (coord.) Reflexiones sobre la violencia en las escuelas (pp. 375-397). México: Siglo XXI.

Saucedo, I. (2010). Identidades de género y violencia: la prevención en el sistema educativo. En Lara, A. (coord.). Género en educación. Temas, avances, retos y perspectivas (pp. 201 -214). México: Universidad Pedagógica Nacional/SNTE/Fundación para la Cultura del Maestro/Plaza y Valdés.

Saucedo, I. (2004). Violencia doméstica y salud: una aproximación al dispositivo de la violencia doméstica en México y la construcción del conocimiento posible" Tesina de Maestría de la Universidad Autónoma de Barcelona.

Scott, J. (1996). El género: una categoría útil para el análisis histórico. En Lamas, M. (comp.). El género: la construcción cultural de la diferencia sexual (pp. 265-302). México, D.F.: Universidad Nacional Autónoma de México-Programa Universitario de Estudios de Género/ Miguel Ángel Porrúa.

Sinués, A. y Jiménez, M. (2010). Los géneros de la violencia. Una reflexión queer sobre la "violencia de género", Madrid: Egales Editorial.

Stolcke, V. (2004). La mujer es puro cuento: la cultura de género. Revista Estudos Feministas, 12(2), 77 - 105. Recuperado de: http://www.scielo.br/pdf/ref/v12n2/23961.pdf.

Young, I. (2000). La justicia y la política de la diferencia. Madrid: Ediciones Cátedra, Universidad de Valencia, Instituto de la Mujer.

Zimbalist, M. (1979). Mujer, cultura y sociedad: una visión teórica. En Harris, O., y Young, K. (Comp.). Antropología y Feminismo (pp. 153-181). Barcelona: editorial Anagrama. Recuperado de: www.cholonautas.edu.pe/modulo/upload/Rosaldo\%20Michelle.pdf. 